\title{
Lugares da crítica na cultura midiática ${ }^{1}$
}

\section{Places of criticism in the media culture}

\author{
Rosana de Lima Soares ${ }^{2}$ \\ Gislene da Silva ${ }^{3}$
}

Resumo Desde a constituição do lugar da crítica como campo teórico, a partir do surgimento de diversos circuitos culturais de produções artísticas, discute-se muito sobre quem deve elou pode fazer a crítica, juízos e valores, finalidades e, mais especialmente, sobre formação de público. No caso específico do incipiente campo de pesquisa da crítica de mídia, tais questões também nos são postas, com destaque para o mesmo movimento pendular historicamente observado em outras instâncias de apreciação de produção cultural, aquele entre teorias abrangentes e análises particulares. Na perspectiva maior do estudo de aportes teóricos, metodológicos e técnicos para uma crítica cultural da mídia, este artigo tem como objetivo discutir a percepção de critérios e valores próprios da crítica de mídia, a interação social entre crítico e públicos, e as teorias da crítica, sempre considerando na grande diversidade de objetos empíricos midiáticos o compartilhamento menos afastado entre produtores e receptores.

Palavras-chave: Crítica de mídia; Práticas discursivas; Cultura audiovisual; Produção jornalística

\footnotetext{
Abstract Since the establishment of the critical place as a theoretical field and the beginning of different cultural circuits of artistic production, there have been many debates about who may and/or can make the critique of art. This debate includes its judgments, values, purposes and, more specifically, the education

1 Artigo originalmente apresentado ao Grupo de Trabalho Cultura das Mídias do XXIII Encontro Anual da Compós, na Universidade de Brasília, de 9 a 12 de junho de 2015.

2 Universidade de São Paulo - USP, São Paulo, SP, Brasil.

E-mail: rosanasoares@gmail.com

${ }^{3}$ Universidade Federal de Santa Catarina - UFSC, Florianópolis, SC. Brasil.

E-mail: gislenedasilva@gmail.com
} 
of the public. The same historical movement present in the cultural area can be observed in the specific case of media criticism's incipient research field, addressing questions concerning comprehensive theories and singular analysis. Focusing on major issues in order to study theoretical, methodological and technical contributions towards a media cultural criticism, this paper intends to present the perception of its criteria and values, the social interaction between critics and audiences, and the criticism theories. The proximity of producers and public will be considered on studing the great variety of media empirical subjects and issues. Keywords: Media criticism; Discursive practices; Audiovisual culture; Journalism production 
Desde a constituição do "lugar da crítica" como campo teórico, a partir do surgimento de diversos circuitos culturais de produções artísticas, discute-se muito sobre quem deve e/ou pode fazer a crítica, juízos e valores, finalidades e, mais especialmente, sobre formação de público. No caso específico do incipiente campo de pesquisa da crítica de mídia, tais questões também se colocam. Na perspectiva maior do estudo de aportes teóricos e técnicos para uma crítica cultural da mídia, este artigo se propõe a discutir a percepção de critérios e parâmetros próprios da crítica de mídia, a interação social entre crítica e público, e as teorias da crítica, sempre considerando na grande diversidade de objetos empíricos midiáticos o compartilhamento menos afastado entre produtores e receptores.

O problema que trazemos para reflexão se configura como parte de um projeto mais abrangente vinculado ao Grupo de Pesquisa Crítica de Mídia e Práticas Culturais (grupo interinstitucional USP/UFSC), criado para a investigação de modalidades de crítica de mídia, sob a inspiração de como se constituíram as críticas de cinema e de literatura, mais consolidadas. Interessam-nos, assim, tanto as críticas que circulam na própria mídia, como as críticas acadêmicas endereçadas aos produtos e processos midiáticos - ambas as interpretações amparadas em estudos da crítica de mídia e da cultura midiática. De grande abrangência empírica, o escopo de nossas pesquisas observa, predominantemente, a produção audiovisual e a produção jornalística, dedicando-se a discursos televisivos, cinematográficos ou digitais on-line e, ainda, à compreensão do jornalismo como produto e produtor de cultura, e ao entendimento da prática noticiosa como experiência cultural.

Além de tratar de grande variedade e volume de objetos empíricos, essa tarefa de pesquisa é também de longo prazo, com vocação para inúmeros desdobramentos, especialmente quando se considera, no caso das pesquisas de pós-graduação, o interesse difuso em analisar criticamente a mídia e o número de mestrandos e doutorandos envolvidos com a problemática. Dentro desse cenário complexo, há também uma lacuna de pesquisa sobre que tipo de crítica de mídia está posta nas inúmeras 
teses e dissertações concluídas, e quais teorias as orientam nesta crítica, implícita ou explicitamente. É nesse quadro cheio de vazios e perspectivas que pesquisadores do grupo elegemos como grande propósito tratar a crítica de mídia como campo próprio de pesquisa e ensino, estudando experiências brasileiras em diálogo com pesquisas internacionais.

$\mathrm{Na}$ conjugação dessas possibilidades e demandas, pensamos que se pode estudar a crítica de mídia em diferentes instâncias ou modalidades:

A. na percepção de parâmetros, do "como fazer para criticar", observando a operacionalização do ofício do crítico e, quando no campo do jornalismo, com atenção para implicações éticas e estéticas da cobertura dos acontecimentos noticiados;

B. no estudo das críticas de mídia que circulam pela própria mídia, feitas por aqueles reconhecidos como críticos, ou seja, que possuem saberes que o público não domina;

C. na crítica de mídia como um gênero textual, praticado pelos especialistas a partir de determinadas convenções reconhecidas pelo público, possibilitando sua circulação junto a ele em espaços já institucionalizados, como jornais, revistas, blogs, colunas, entre outros;

D. nas experiências metacríticas, em termos de conteúdo e forma, das inovações estéticas e estilísticas veiculadas na própria mídia, que, ao propor um novo formato ou gênero, empreendem uma crítica àquilo estabelecido como padrão, realizando-a não como uma análise sobre a mídia, mas no próprio fazer midiático;

E. nas interações sociais de crítica, nas quais receptores criticam de maneira dispersa e informal materiais veiculados nas mídias e também revelam em suas críticas imagens sociais que têm dos diversos meios e práticas, confirmando ou questionando fundamentos da produção midiática, como acontece, por exemplo, no caso da divulgação de notícias;

F. nos modos de leitura e perfis do público de crítica de mídia;

G. no estudo das "teorias da crítica", teorizando sobre os modos de "como fazer para criticar" e de "como criticam os que criticam", 
seja com foco nas práticas de críticos na mídia, seja nas pesquisas acadêmicas;

H. e, no que diz respeito à especificidade do jornalismo, a crítica de mídia noticiosa como recurso didático-pedagógico para ensino e formação de profissionais.

Dentre essas modalidades, como dissemos, destacamos no momento a conjugação de três delas: a percepção de critérios e valores próprios da crítica de mídia, a interação social entre crítica e público, e as teorias da crítica, tentando uma resposta inicial para: Quais seriam os "modos de se fazer a crítica de mídia”, de elaborar conceitos e critérios para sua realização? Antes, porém, de nos debruçarmos sobre esses aspectos e seguirmos na indagação inicial sobre os "lugares da crítica de mídia", julgamos ser relevante retomar resumidamente alguns de seus pressupostos, da década de 1960 até anos mais recentes.

\section{Crítica de mídia e perspectivas do pensamento crítico}

Herdeiro do media criticism em sua vertente norte-americana, desde seu início o pensamento crítico sobre os meios de comunicação constituiu-se a partir de diferentes perspectivas. Na vertente europeia - na qual se incluem as correntes desenvolvidas no Brasil -, ele organizou-se em torno da teoria crítica advinda da Escola de Frankfurt; na vertente americana, voltou-se para a avaliação ou monitoramento do desempenho dos meios tendo como referência valores socialmente assentados. Nas palavras de Freitas, duas tendências se apresentam ao tomarmos esse campo de pesquisa:

$\mathrm{Na}$ perspectiva da "teoria crítica", partindo do marxismo, a discussão se dá em torno das questões do poder e da dominação, da propriedade dos meios e da luta de classes; ao passo que, na perspectiva do media criticism, os estudos objetivam a análise dos media tendo como padrão referencial a concordância com as ideias e anseios que determinada sociedade se propõe, com estatutos éticos os quais os regimes de governo deverão observar, com ideais profissionais que orientam as práticas (FREITAS, 1991, p. 88). 
Sob o viés da teoria crítica frankfurtiana, podemos reconhecer, alargando sua abrangência, veículos da imprensa alternativa ou da mídia independente, estudos sobre a qualidade da produção midiática, iniciativas para o letramento, ou media literacy, e aquelas visando uma leitura crítica das mídias. De modo análogo, ao observarmos o alcance do media criticism encontramos forte presença na crítica ao jornalismo, especialmente o impresso, como também o televisivo e, mais recentemente, o digital, por meio de colunas publicadas nos próprios jornais, presença de ombudsmen e criação de observatórios de mídia, responsáveis pelo acompanhamento sistemático da produção e desempenho dos meios. É nesse cenário multifacetado e poroso que vemos também a produção acadêmica sobre crítica de mídia disposta em duas direções: na realização efetiva de análises críticas sobre formas e conteúdos midiáticos; ou em pesquisas dedicadas ao estudo das críticas produzidas nas/ pelas mídias.

Nesse panorama, uma ausência se manifesta: um lugar para a crítica de mídia que estabeleça a ligação entre as práticas midiáticas e as análises sobre seu impacto social. Tal liame fazia-se essencial para a consecução, pelo menos até os anos 1980, de duas importantes funções do media criticism: o acompanhamento dos meios e a comunicação com o receptor, colaborando "para a melhoria dos padrões éticos, culturais e profissionais desse desempenho e estendendo-se aos destinatários dos meios contribuindo para a formação de públicos seletivos, articulados e dotados da capacidade de discernimento e de julgamento" (FREITAS, 1991, p. 89).

Essa concepção, ainda segundo Freitas, compreende que a crítica pressupõe uma dada representação da sociedade, realizando a análise dos meios a partir desta representação, ou seja, de certo modo, o que vemos em circulação nas mídias faz parte de uma cultura constituída que é devolvida à sociedade como uma autoimagem que nela se perpetua, reafirmando seus valores fundantes: "Os padrões estabelecidos são relacionais, isto é, baseiam-se em valores. É justamente o acordo sobre esses valores que tornam os padrões válidos e universais. A integração da 
crítica ao sistema verifica-se exatamente através da função de supervisionar ou controlar a efetivação desses padrões" (FREITAS, 1991, p. 91).

Atualizando a problemática a respeito do potencial conservador ou transgressor da crítica, Rancière indaga sobre a possibilidade de ruptura pressuposta na atividade artística. Ao tratar das relações entre política e estética, o autor nos apresenta dois modelos, revistos aqui de modo sintético: o "pedagógico", direcionado para a formação do público a partir de bases preestabelecidas (entre elas, o funcionalismo e a teoria crítica, muitas vezes focadas no conteúdo dos objetos analisados); e o "transformador", interessado na partilha do sensível por meio da busca pela emancipação e pelo reconhecimento do espectador (baseado na ausência de uma origem ou uma finalidade, e desencadeando processos de identificação). Para o autor, o papel da arte seria o de criar ficções alternativas em relação àquelas tidas como consensuais: "As práticas da arte não são instrumentos que forneçam formas de consciência ou energias mobilizadoras em proveito de uma política que lhes seja exterior, mas tampouco saem de si mesmas para se tornarem formas de ação política coletiva. Contribuem para desenhar uma paisagem nova do visível, do dizível e do factível" (RANCIÈRE, 2012, p. 75).

A intervenção da arte nas relações sociais não seria automaticamente alcançada, mas oferece, nesse caso, a possibilidade de interferir na partilha do sensível, forjando "contra o consenso outras formas de "senso comum', formas de um senso comum polêmico” (RANCIÈRE, 2012, p. 75). A partir dessas reflexões, afirmamos que a potência crítica não estaria apenas no próprio objeto (não é interna), mas também fora dele (no contexto e na recepção). Ou seja, não haveria um modo único de apresentação da realidade ou algo que precisa ser desvelado, mas a reconfiguração do sensível sob outros modos de percepção e significação: "A inteligência coletiva da emancipação não é a compreensão de um processo global de sujeição. É a coletivização das capacidades investidas nessas cenas de dissenso" (RANCIÈRE, 2012, p. 49). Diferentemente da proposição engendrada pelo media criticism, que pressupõe menor conhecimento do público em relação aos especialistas, se estendermos 
as considerações já apresentadas para as práticas midiáticas, podemos notar uma dinâmica de retroalimentação entre produtores/autores e receptores/espectadores que interfere e modifica os produtos e processos nelas presentes.

Como podemos ver, diversas correntes de pensamento fornecem aportes, de modo mais ou menos direto, para nos guiar nessa investigação, já que cada visada "analítica" pressupõe uma perspectiva "filosófica" e uma experiência "histórica”. É assim que vemos desdobrarem-se possibilidades críticas a partir de estudos de autoria; estudos culturais; estudos de gênero; estudos de recepção; dialogismo; análise de discurso; gêneros discursivos; retórica; hermenêutica; mitologia; história; sociologia; estruturalismo; etnografia; tecnologias. Nos anos 1990, ao tratarem da crítica televisiva, Vande Berg e Wenner (1991) realizaram um empreendimento original para os estudos de mídia: reconhecendo o amadurecimento das análises sobre televisão, os autores apresentam os caminhos teóricos nos quais esse meio é estudado, por meio de diversas abordagens e aplicações. Antes, ainda na década de 1970, Newcomb (2007) já publicara uma importante obra sobre crítica de televisão e, nos anos 2000, Davin e Jackson (2008), entre outros, atualizaram a temática com novas análises críticas.

Mais do que apresentar estudos de caso sobre programas televisivos de gêneros variados, de maior ou menor reconhecimento (seja em termos de qualidade, audiência ou inovação) - e que poderiam ser substituídos por outros, mais atuais -, Vande Berg e Wenner (1991) sublinham duas questões: primeiramente, demonstram a variedade de vieses crítico-teóricos e interpretações possíveis para os estudos de televisão; depois, salientam a singularidade de tais estudos em relação ao lugar de fala assumido por cada um dos pesquisadores, que trazem para as análises assunções e percepções enquanto telespectadores que experienciam maneiras distintas de ver televisão. Ao empreender essa dupla articulação, o livro nos mostra ao menos três aspectos fundamentais para a crítica de mídia hoje, seja ela televisiva, cinematográfica, musical, jornalística, radiofônica, digital: não há possibilidade de se ter um consenso 
sobre os modos de se fazer a crítica de mídia; não é possível realizá-la sem levar em conta suas condições de produção e recepção; não se pode também fazer a crítica sem olhar objetos concretos/empíricos (produtos, processos e discursos) efetivamente em circulação nas mídias.

A atividade crítica seria, portanto, eminentemente plural, construída a partir de diferentes perspectivas visando relacionar produtores, obras e públicos "em modos próprios de discernimento, pondo em ação variada gama de métodos analíticos e de procedimentos explicativos ou compreensivos" (NUNES, 2007, p. 61-62). Estamos falando nos grandes paradigmas que orientam os modos de se fazer crítica cultural, que podem também orientar a crítica de mídia, quando tomamos aquelas questões cruciais: quem está autorizado a fazer a crítica, qual sua finalidade, os juízos e valores nela implicados, a formação de público, entre outras. No momento, para além dessas, queremos enfatizar uma indagação sobre as diferentes maneiras de se praticar a crítica de mídia, que apontam para duas tendências no modo de abordar o objeto criticado: a de teorias abrangentes sobre a mídia e a de análises particulares de produtos midiáticos.

Em artigo anteriormente publicado, Silva e Soares (2013) discutem que a crítica de mídia deveria, conforme percepção de Braga, "abandonar juízos totalizantes sobre os meios de comunicação, endereçando-os aos produtos midiáticos" (BRAGA, 2006, p. 17). O que Braga sugere é irmos da análise generalizada para aquela mais específica, recortando das mídias produtos singulares, a fim de reconhecer o repertório ali articulado. De modo semelhante, Machado segue na direção de análises particulares, assinalando, no caso da televisão, para a constituição de um "acervo heterogêneo de trabalhos audiovisuais" que deve ser abordado a partir de uma "perspectiva valorativa" inscrita na materialidade de seus programas (MACHADO, 2008, p. 24). A afirmação de Braga, aqui destacada, fornece um caminho para tal empreendimento: "Quanto mais desenvolvidos sejam os dispositivos críticos, mais provavelmente eles se voltam para uma análise de produtos específicos (e menos para análises do meio em sua generalidade)" (BRAGA, 2006, p. 61). 
O argumento em defesa é que, ao olhar para o particular, os critérios orientadores do "como fazer a crítica" tornam-se mais visíveis e palpáveis. De acordo com Braga, "fazer perguntas mais específicas sobre produtos singulares é o que viabiliza perceber estruturações diferenciadas, fazer julgamentos mais finos sobre qualidade e mais relacionados a critérios expressos (uma vez que 'qualidade' não é um valor absoluto ou definível na ausência de referências sociais)” (BRAGA, 2006, p. 53). Para o desenvolvimento do processo de crítica de mídia, ele observa que, mesmo diante das dificuldades em se alcançar "gêneros e dispositivos críticos estáveis", há que se investir na necessidade de se "estudar os ângulos mais promissores de análise, desenvolver cada um deles em termos de sistematização aberta, percepção explícita de seus enfoques, objetivos e resultados concretos", tanto para o conhecimento do objeto midiático quanto para a capacidade interpretativa dos receptores (BRAGA, 2006, p. 274).

O que temos, então, é uma espécie de disputa entre perspectivas de se fazer crítica de mídia: uma que opta por análises de particulares e outra que busca análises mais gerais, de totalidades. Esta tensão foi tratada por França em publicação recente. A pesquisadora discute o caráter cíclico das abordagens críticas da comunicação nos últimos 40 anos no Brasil, reafirmando a importância do resgate de olhares mais abrangentes, capazes de interpretar as práticas comunicativas na sua relação com a manutenção ou a mudança social. Lembra que nos anos 1970 e 1980, as teorias denunciavam a mercantilização da cultura, o esvaziamento do simbólico, as disputas por hegemonia na interpretação da realidade. "Os 20 anos seguintes foram marcados por certo abandono do viés crítico, em favor de abordagens mais pontuais, do tratamento de aspectos mais recortados do processo e do produto comunicativo" (FRANÇA, 2014, p. 101).

Amparada nas reflexões recentes de Boltanski (2009), França sugere acolher a síntese realizada pelo sociólogo francês quando, depois de longa trajetória em direção a práticas específicas, ele se volta para a mútua dependência e a complementaridade entre a "crítica" e a "metacrítica", 
pondo em destaque os limites da sociologia pragmática da crítica, uma vez que se perde nela a noção de totalidade - e sem essa perspectiva abrangente não se conseguiria passar da crítica fragmentada e particular dos atores a uma visada crítica global da sociedade. França vem reclamar por uma permanente visada crítica nos estudos comunicacionais, "uma perspectiva que, atenta ao específico e ao singular, não se feche em objetos e raciocínios autossuficientes, e possa sempre reenviar esses objetos ao contexto maior no qual eles existem, atuam, condicionam e sofrem condicionamentos" (FRANÇA, 2014, p. 114). Sua preocupação não é solitária entre os pesquisadores brasileiros. Também Braga conclui, ao final, pela necessidade de "uma construção conceitual do trabalho crítico-interpretativo, baseada em referências aos principais processos e perspectivas vigentes do 'fazer crítica' sobre mídia” (BRAGA, 2006, p. 67), que seria uma construção conceitual elaborada para ampliação e diversificação do escopo da crítica, em função de seus objetivos sociais.

\section{Lugares em movimento}

Se estamos todos mergulhados na cultura das mídias - e a própria crítica acadêmica nela se insere -, o questionamento sobre os "lugares da crítica" se expande e retorna, de modo ampliado, às questões iniciais: Quem pode fazer a crítica da crítica? O que pode fazer a crítica acadêmica? Uma possível indicação seria dizer que a crítica de mídia deve evidenciar pontos de vista dissonantes sobre as mídias e problematizar formatos considerados hegemônicos. Nesse sentido, além de apontar estabilidades ou reafirmar gêneros já reconhecidos, a crítica de mídia seria um lugar de questionamento e ruptura no interior dos próprios meios de comunicação.

Se, como afirmara De Certeau (1994), o cotidiano é o locus em que diversos relatos convivem de maneira conflituosa e assimétrica na disputa por espaços de hegemonia, as práticas discursivas amplificam as diferentes vozes sociais por meio de estruturas interpretativas compartilhadas, entendidas como sistemas de significação: "Indissociável do 'instante' presente, de circunstâncias 'particulares' e de um 'fazer' 
(produzir língua e modificar a dinâmica de uma relação), o ato de falar é um uso da língua e uma operação ‘sobre’ ela” (DE CERTEAU, 1994, p. 96). Sendo assim, o autor propõe a delimitação de tais operações por outro prisma, não enquanto relacionadas a um sistema fechado, mas como “'relações de forças' definindo as redes onde se inscrevem e delimitam as circunstâncias de que podem aproveitar-se. (...) Trata-se de combates ou de jogos entre o forte e o fraco, e das ações que o fraco pode empreender" (DE CERTEAU, 1994, p. 97).

Caberia à crítica de mídia acionar repertórios constituintes do imaginário social a fim de reiterar ou reverter certos discursos. Como se realizasse uma volta sobre si mesma, a crítica - transformada em metacrítica (cf. FUCHS, 2010) - busca códigos da cultura midiática para devolvê-los às próprias mídias, retornando o que delas havia tomado ao empreender uma interpretação para além dos lugares comuns nela recorrentes. Ao assumir uma perspectiva crítica ao olhar as mídias, ainda que seja a partir de seu interior, o analista se posiciona em relação à qualidade - valores e critérios - dos produtos examinados, voltando-se para a sociedade e seus parâmetros de julgamento, interferindo, assim, nas disputas em jogo no campo simbólico.

Como mostramos anteriormente, há pelo menos duas possibilidades para a crítica de mídia quando vista sob esse ângulo: por um lado, realizar uma análise das mídias que seja de fato crítica e, por outro, pensar o lugar da crítica como desconstrução de discursos cristalizados. Se não ocorre esse duplo movimento, ou uma 'dobra' da crítica sobre ela mesma, vemos se multiplicarem, nas mídias, análises opinativas ou superficiais que se denominam "críticas", mas, na verdade, apenas repetem o já sabido sem demonstrar aquilo que afirmam. Dessa forma, como dissemos, é papel da universidade não apenas fazer a crítica de mídia, mas também estudar a crítica que dela é feita, apontando aspectos relativos aos modos de construção da enunciação dos diferentes discursos midiáticos e de problematização da sociedade no qual estão inseridos. Ao fazê-lo, a crítica de mídia se torna também a crítica dos modos pelos quais é construída a representação - ou o visível - e se volta não apenas 
para aspectos da produção, mas também da recepção e da formação do público, de um público que, como vimos, também participa do circuito da crítica.

Se a atividade crítica, enquanto método que busca examinar as práticas midiáticas, pressupõe valores e critérios, é necessário que tanto os conceitos usados em suas análises, bem como a práxis para a qual se voltam, reconheçam os objetos empíricos analisados como sintomas de uma determinada época histórica, colocando-os em crise. É nesse intuito que podemos afirmar que a atividade crítica é um lugar de fala que depende do lugar de quem vê, determinando o que pode ou não ser visto e, ainda, para quem se dirige essa fala.

As questões levantadas até aqui nos apontam, assim, três aspectos fundamentais para um estudo sistemático da crítica de mídia. O primeiro deles diz respeito à demarcação daquilo que pode ser alocado sob essa rubrica; o segundo indaga os modos de sua realização e difusão; e o terceiro visa delimitar os objetos específicos aos quais a crítica de mídia poderia se dedicar. Tais exercícios de constante observação e distinção de produtos midiáticos se realizariam tanto a partir de escolhas teórico-metodológicas em pesquisas científicas, como fora do âmbito acadêmico, por especialistas atuantes no campo da divulgação jornalística, por públicos e por produtores.

\section{Considerações finais}

Ao longo do artigo, levantamos alguns pressupostos que acreditamos interessantes para análises das mídias que se pretendam críticas e, além disso, para o estudo da crítica feita na/pela mídia. Em termos gerais, enfatizamos que criticar significa desenhar os limites que colocam o objeto em crise, expandindo-o para além de suas relações textuais mais intrínsecas. Entendemos que, ao mesmo tempo, são estas mesmas vinculações que delineiam sua inserção discursiva e sua circulação nas mídias, o que assinala um ponto de virada em relação à crítica de arte tradicional. Sem incorrermos em hierarquizações que recoloquem no debate a divisão 
entre alta e baixa cultura, ou entre a cultura popular, massiva e erudita, é no campo da cultura midiática que o inserimos.

Ressaltamos, portanto, uma demarcação entre a crítica que surge na modernidade para pensar padrões de julgamento diante de objetos nascentes - ou seja, para explicar aos "leigos" uma nova arte não facilmente assimilável - e a crítica contemporânea, especialmente aquela voltada para as mídias, da qual cada um de nós toma parte em diferentes posições, indagando sobre a falência ou a atualidade da crítica. Nas palavras de Didi-Huberman encontramos eco para nossas inquietações:

Precisamos doravante reconhecer esse movimento dialético em toda sua dimensão "crítica", isto é, ao mesmo tempo em sua dimensão de crise e de sintoma - como o turbilhão que agita o curso do rio -, e em sua dimensão de "análise crítica", de reflexividade negativa, de intimação - como o turbilhão que revela e acusa a estrutura, o leito mesmo do rio (DIDI-HUBERMAN, 1998, p. 171).

Seja como crise, seja como sintoma, é inquestionável a relevância de se pensar o lugar da crítica hoje, atravessada por injunções tecnológicas e por uma cultura midiática irradiada no tecido social. Ao nos encaminharmos para as provisórias conclusões desse exercício de pensamento sobre a crítica de mídia, uma obra recente pode nos auxiliar no retorno a alguns pontos e na projeção de outros. No filme argentino $O$ crítico (2014), de Hernán Guerschuny, além do título que destaca essa função, vemos o personagem principal, um exigente crítico de cinema, prestigiado nos jornais para os quais escreve e conhecido por seu rigor na análise de películas, voltar-se contra a produção atual. Curiosamente, são os filmes de gênero aqueles que mais sofrem com seus ataques, especialmente as comédias românticas, para ele um subproduto do que um dia teria sido "a grande arte". No início da narrativa ouvimos o crítico dizer abertamente que "o cinema está morto" e que suas melhores produções encontram-se no passado. Solitário e amargo, o personagem se vê envolvido, inadvertidamente, em uma trama romântica sobre a qual não tem controle. Começam assim as reviravoltas da história e seu aparato metalinguístico coloca-se em operação nas várias camadas 
narrativas do filme. Ao mesmo tempo em que assistimos à desconstrução do gênero em questão, somos envolvidos em um filme que replica e atualiza seus clichês.

O jogo narrativo não se dá apenas no plano dos enunciados, mas também na enunciação, envolvendo o espectador de forma ativa. Temos, assim, um filme de gênero que se constrói em perspectiva autoral (oscilando entre essas duas narrativas) e que, além de evocar um gênero consolidado - as comédias românticas -, dirige a ele uma crítica severa ao mesmo tempo em que propõe sua renovação, subvertendo a matriz norte-americana de humor e amor, reinventando-a com cores locais. Ao desconstruir a forma genérica da qual toma parte para construí-la de outro modo, notamos aproximações e distanciamentos em relação aos traços distintivos das comédias românticas. Como em outras produções recentes, "o filme evoca ecos (redundâncias) em relação ao padrão estabelecido e também rupturas (ressonâncias) que o diferenciam deste padrão, apresentando uma forma genérica como lugar experimental de passagem e não como fixação de um destino" (SOARES, 2006, p. 174).

Nesse sentido, a crítica não é feita do exterior, mas a partir do próprio tecido fílmico; vale dizer, o filme ao qual assistimos realiza, nele mesmo, tal movimento, compondo uma crítica na forma da expressão e não apenas na forma do conteúdo: "Entendendo-se o gênero como um lugar exterior à obra, de onde o sentido da narrativa é produzido e consumido, ou seja, através da convenção, a obra se dirigiria para fora de si, acionaria a sua capacidade de comunicar" (FOLLAIN, 2010, p. 59). Mas um fator singular se destaca: a maneira metalinguística com que o filme recusa e exalta as comédias românticas se materializa na figura do crítico - posição que dá nome ao filme -, ou seja, instaura-se como uma segunda dobra na crítica que o filme faz e naquela feita em seu interior a respeito dos mesmos filmes com os quais compartilha este gênero cinematográfico. Em artigo que trata de romances policiais, Follain chama atenção para uma recorrência em obras contemporâneas, sejam elas literárias ou cinematográficas: agradar ao público e possibilitar seu reconhecimento 
nas histórias contadas e, ao mesmo tempo, manter a dimensão crítica da obra por meio de diferentes níveis de leitura.

Nas palavras da autora, por um lado, "preserva-se o enredo, sem preconceito para com aquele leitor que busca divertir-se com a intriga", assegurando sua identificação com a narrativa. Por outro, "oferece-se algo além da intriga, uma dimensão metalinguística e reflexiva, reforçada por inúmeras citações, que permite a um outro tipo de leitor contemplar, de maneira distanciada e também nostálgica, as estratégias narrativas que criam o fascínio na primeira dimensão" (FOLLAIN, 2010, p. 61). É assim que vemos o crítico, que odeia comédias românticas, passar a viver, em seu cotidiano, as convenções e inovações genéricas do formato que despreza. Outra artimanha duplica essa dobra: o personagem que tem na crítica cinematográfica sua vocação é chamado a escrever um roteiro. O filme por ele imaginado mimetiza sua própria vida e reproduz, passo a passo, os elementos constitutivos das comédias românticas por ele desprezadas e, em suas palavras, consolidadas em uma forma narrativa evidente, como se percebe em inúmeros filmes de qualidade duvidosa.

Esse movimento pode ser identificado no diálogo inusitado entre o personagem e uma garota pela qual ele se apaixona. Ao ser por ela questionado sobre seu trabalho, o crítico responde que "escreve críticas de filmes" e que é "um intermediário entre os filmes e o público". O personagem apresenta, em tom solene, seu ofício: "Graças ao meu trabalho, as pessoas podem discernir uma obra de arte de um produto ruim”. Retornamos, aqui, ao ponto inicial do texto - e do lugar tradicional da crítica - e, de modo espiralado, ao ponto final de artigo anteriormente apresentado (SILVA; SOARES, 2013). Naquela ocasião, Follain nos interpelava a respeito de dois pontos fundamentais, que esperamos tenham encontrado um destino no texto agora ensaiado. O primeiro diz respeito às diferenças entre a crítica de arte e a crítica de mídia, e a adequação do modelo de uma à outra. $\mathrm{O}$ segundo se refere à função da crítica na proposição de critérios de distinção extrínsecos às obras analisadas, o que recolocaria para as mídias a separação entre produtos culturais qualificados ou aqueles de entretenimento trivial. 
Entre formar de maneira autoral o (bom) gosto do público e participar ativamente de um gênero comum, o lugar da crítica de mídia em face de uma produção bastante diversificada, como anota Follain (2013), afasta-se daquele realizado pela crítica de arte, "tributária do processo de constituição da arte como campo autônomo, tendo como pressuposto a sua dissociação de outras esferas" (FOLLAIN, 2013)4.

Um ponto de virada se apresenta para a continuidade de nossos estudos: a maior acessibilidade e proximidade da cultura midiática com o gosto vigente, nas palavras de Follain (2010), tornaria dispensável a mediação de intérpretes - a exemplo do crítico no filme sobre a atividade crítica. Entretanto, ao investirem em produtos de consumo ligeiro e sucesso comercial (como as comédias românticas do crítico), as mídias perderiam sua potência transformadora e irruptiva se pensadas a partir dos critérios da crítica de arte. Concordamos que tal fato não seja, em si mesmo, nem positivo, nem negativo, vislumbrando nele uma trilha a ser percorrida para buscar parâmetros pelos quais pensarmos as singularidades da crítica de mídia.

Para Follain (2010), "se a obra moderna de ficção era, por definição, uma obra difícil de interpretar, despertando um sentimento de estranheza, causando um choque no leitor, a obra pós-moderna quer se fazer passar como algo familiar, cabendo ao público com mais repertório desconfiar dessa familiaridade e recuperar a sua dimensão complexa, encoberta por esta aparente simplicidade" (FOLLAIN, 2010, p. 62). Ousamos dizer que, se considerados os elementos discutidos neste artigo, podemos vislumbrar espaços de inovação, que deverão ser confirmados em análises futuras ao serem confrontados com objetos empíricos específicos. Encontrar aberturas críticas em torno de produtos ordinários, porque da vida comum, não significa evocar o papel da crítica cultural tradicional para a cultura midiática, o que resultaria justamente em esvaziamento da crítica.

\footnotetext{
${ }^{4}$ Vera Follain de Figueiredo em seu relato sobre o trabalho de SILVA, G. e SOARES, R. L. no GT Cultura das Mídias, no XXII Encontro Anual da Compós, Salvador, UFBA, 2013.
} 
Se pensada de modo dinâmico, a crítica midiática pode ser percebida como uma espécie de entre-lugar, em que diversos campos misturam suas especificidades e se renovam. E ao privilegiar as conexões entre as diversas práticas midiáticas, a atividade crítica possibilita a inserção de determinado objeto midiático em uma rede de relações geradora de novos sentidos, observando e articulando suas implicações históricas, políticas, sociais, culturais e econômicas. Só que, na crítica de mídia, os juízos de valor a que se pode recorrer para efetuá-la são compartilhados de modo muito mais entrelaçado com públicos e audiências do que costumamos ver em práticas de críticas literárias e mesmo de cinema. Nessa perspectiva, a crítica de mídia deveria ser feita com critérios e valores a ela internos, já que os públicos para os quais se volta compartilha, em diferentes medidas, a mesma cultura midiática, dela participando e nela interferindo.

Logo, muitos e diversos desafios se colocam para a tarefa da pesquisa sobre crítica de mídia no Brasil. Este artigo se propôs a sugerir caminhos pelos quais sistematizar e problematizar a crítica de mídia, tanto naquilo que se projeta em relação a seus procedimentos, quanto no que se reconhece em termos de sua realização, com enfoque na especificidade de aportes teóricos e técnicos para uma crítica cultural da mídia. Resta-nos, portanto, recortar de uma gama variada de práticas midiáticas aquelas que poderão ser analisadas a fim de confirmar ou refutar hipóteses de trabalho. Apostamos, tanto no âmbito acadêmico quanto na esfera dos especialistas e do público, que uma brecha se abra para esse percurso. Esperamos desenvolver alguns de seus trajetos em próximas investigações. 


\section{Referências}

BOLTANSKY L. De la critique. Précis de sociologie de l'émancipation. Paris: Gallimard, 2009.

BRAGA, J. L. A sociedade enfrenta sua mídia: dispositivos sociais de crítica midiática. São Paulo: Paulus, 2006.

DAVIN, S.; JACKSON, R. (Ed.). Television and criticism. Bristol: Intellect Books, 2008. DE CERTEAU, M. A invenção do cotidiano. Artes de fazer. 2. ed. Petrópolis: Vozes, 1994.

DIDI-HUBERMAN, G. O que vemos, o que nos olha. São Paulo: Editora 34, 1998.

FOLLAIN DE FIGUEIREDO, V. L. Narrativas migrantes. Literatura, roteiro e cinema. Rio de Janeiro: 7 Letras, 2010.

FUCHS, C. Alternative media as critical media. European Journal of Social Theory, v. 13, n. 2, p. 173-192, 2010.

FRANÇA, V. R. V. Crítica e metacrítica: contribuição e responsabilidade das teorias da comunicação. MATRIZes, São Paulo, v. 8, n. 2, p.101-116, jul./dez. 2014.

FREITAS, J. M. M. A crítica na tradição norte-americana (journalism review). Cadernos de Jornalismo e Editoração, São Paulo, v. 12, n. 28, p. 87-99, dez. 1991.

MACHADO, A. Televisão: a questão do repertório. In: BORGES, G.; REIA-BAPTISTA, V. Discursos e práticas de qualidade na televisão. Lisboa: Livros Horizonte/UAL-Ciac, 2008.

NEWCOMB, H. (Ed.). Television - The critical view. $7^{\text {th }}$ ed. Oxford: Oxford University Press, 2007.

NUNES, B. Crítica literária no Brasil, ontem e hoje. In: MARTINS, M. H. Rumos da crítica. 2. ed. São Paulo: Editora Senac, 2007.

RANCIÈRE, J. O espectador emancipado. São Paulo: Martins Fonte, 2012.

SILVA, G.; SOARES, R. L. Para pensar a crítica de mídias. Revista Famecos (On-line), v. 20 , p. $820-839,2013$.

SOARES, R. L. Essa não é mais uma história de amor. In: SANTANA, G.; LYRA, B. Cinema de bordas. São Paulo: a Lápis, 2006.

VANDE BERG, L. R.; WENNER, L. A. Television criticism: approaches and applications. New York: Logman, 1991. 


\section{Sobre os autores}

Rosana de Lima Soares - Professora livre-docente da Escola de Comunicações e Artes da Universidade de São Paulo, com pós-doutorado no King's College London (Inglaterra). Líder do Grupo de Pesquisa Crítica de Mídia e Práticas Culturais. Bolsista de Produtividade em Pesquisa (CNPq).

Gislene da Silva - Professora do Programa de Pós-Graduação em Jornalismo da Universidade Federal de Santa Catarina, com pós-doutorado na ECA-USP e na Universidad Complutense de Madrid (Espanha). Líder do Grupo de Pesquisa Crítica de Mídia e Práticas Culturais. Bolsista de Produtividade em Pesquisa (CNPq).

Data de submissão: 19/01/2016

Data de aceite: 30/06/2016 